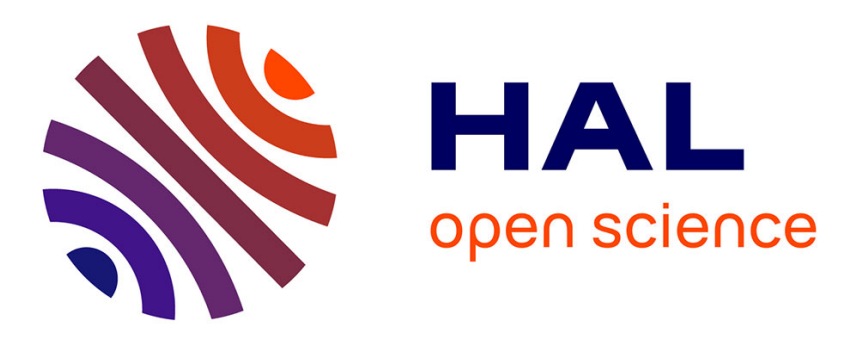

\title{
Solving multi-criteria decision problems under possibilistic uncertainty using optimistic and pessimistic utilities
}

\author{
Nahla Ben Amor, Fatma Essghaier, Hélène Fargier
}

\section{To cite this version:}

Nahla Ben Amor, Fatma Essghaier, Hélène Fargier. Solving multi-criteria decision problems under possibilistic uncertainty using optimistic and pessimistic utilities. International Conference on Information Processing and Management of Uncertainty in Knowledge-based Systems (IPMU 2014), Jul 2014, Montpellier, France. pp.269-279, 10.1007/978-3-319-08852-5_28 . hal-01109805

\section{HAL Id: hal-01109805 \\ https://hal.science/hal-01109805}

Submitted on 27 Jan 2015

HAL is a multi-disciplinary open access archive for the deposit and dissemination of scientific research documents, whether they are published or not. The documents may come from teaching and research institutions in France or abroad, or from public or private research centers.
L'archive ouverte pluridisciplinaire HAL, est destinée au dépôt et à la diffusion de documents scientifiques de niveau recherche, publiés ou non, émanant des établissements d'enseignement et de recherche français ou étrangers, des laboratoires publics ou privés. 


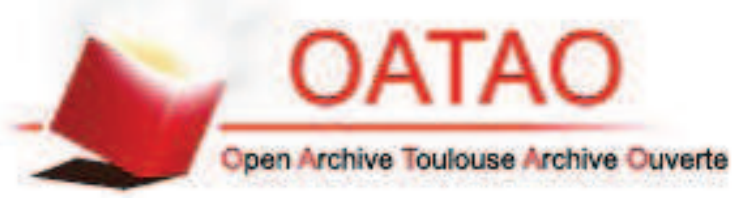

Open Archive TOULOUSE Archive Ouverte (OATAO)

OATAO is an open access repository that collects the work of Toulouse researchers and makes it freely available over the web where possible.

This is an author-deposited version published in: http://oatao.univ-toulouse.fr/ Eprints ID : 13240

To cite this version : Ben Amor, Nahla and Essghaier, Fatma and Fargier, Hélène Solving multi-criteria decision problems under possibilistic uncertainty using optimistic and pessimistic utilities. (2014) In: International Conference, Information Processing and Management of Uncertainty in Knowledge-based Systems (IPMU), 15 July 2014 - 19 July 2014 (Montpellier, France).

Any correspondance concerning this service should be sent to the repository administrator: staff-oatao@,1istes-diff.inp-toulouse.fr 


\title{
Solving multi-criteria decision problems under possibilistic uncertainty using optimistic and pessimistic utilities
}

\author{
Nahla Ben Amor ${ }^{1}$, Fatma Essghaier ${ }^{1,2}$, and Hélène Fargier ${ }^{2}$ \\ 1 LARODEC, Institut Supérieur de Gestion Tunis, Tunisie \\ 2 IRIT-CNRS, UMR 5505 Université de Toulouse, France \\ nahla.benamor@gmx.fr, essghaier.fatma@gmail.com , fargier@irit.fr
}

\begin{abstract}
This paper proposes a qualitative approach to solve multicriteria decision making problems under possibilistic uncertainty. Depending on the decision maker attitude with respect to uncertainty (i.e. optimistic or pessimistic) and on her attitude with respect to criteria (i.e. conjunctive or disjunctive), four ex-ante and four ex-post decision rules are defined and investigated. In particular, their coherence w.r.t. the principle of monotonicity, that allows Dynamic Programming is studied.
\end{abstract}

\section{Introduction}

A popular criterion to compare decisions under risk is the expected utility model $(E U)$ axiomatized by Von Neumann and Morgenstern [9]. This model relies on a probabilistic representation of uncertainty: an elementary decision is represented by a probabilistic lottery over the possible outcomes. The preferences of the decision maker are supposed to be captured by a utility function assigning a numerical value to each consequence. The evaluation of a lottery is then performed through the computation of its expected utility (the greater, the better). When several independent criteria are to be taken into account, the utility function is the result of the aggregation of several utility functions $u_{i}$ (one for each criterion). The expected utility of the additive aggregation can then be used to evaluate the lottery, and it is easy to show that it is equal to the additive aggregation of the mono-criterion expected utilities.

These approaches presuppose that both numerical probability and additive utilities are available. When the information about uncertainty cannot be quantified in a probabilistic way the topic of possibilistic decision theory is often a natural one to consider. Giving up the probabilistic quantification of uncertainty yields to give up the EU criterion as well. The development of possibilistic decision theory has lead to the proposition and the characterization of (monocriterion) possibilistic counterparts of expected utility: Dubois and Prade [3] propose two criteria based on possibility theory, an optimistic and a pessimistic one, whose definitions only require a finite ordinal scale for evaluating both utility and plausibility. Likewise, qualitative approaches of multi-criteria decision 
making have been advocated, leading to the use of Sugeno Integrals (see e.g. [1, $8]$ ) and especially weighted maximum and weighted minimum [2].

In this paper, we consider possibilistic decision problems in the presence of multiple criteria. The difficulty is here to make a double aggregation. Several attitudes are possible: shall we consider the pessimistic/optimistic utility value of a weighted min (or max)? or shall we rather aggregate with a weighted min (or $\max$ ) the individual pessimistic (or optimistic) utilities provided by the criteria? In short, shall we proceed in an ex-ante or ex-post way?

The remainder of the paper is organized as follows: Section 2 presents a refresher on possibilistic decision making under uncertainty using Dubois and Prade's pessimistic and optimistic utilities, on one hand, and on the qualitative approaches of MCDM (mainly, weighted min and weighted max), on the other hand. Section 3 develops our proposition, defining four ex-ante and four ex-post aggregations, and shows that when the decision maker attitude is homogeneous, i.e. either fully min-oriented or fully max-oriented, the ex-ante and the ex-post possibilistic aggregations provide the same result. Section 4 studies the monotonicity of these decision rules, in order to determine the applicability of Dynamic Programming to sequential decision making problems. ${ }^{1}$

\section{Background on one-stage decision making in a possibilistic framework}

\subsection{Decision making under possibilistic uncertainty $\left(U^{+}\right.$and $\left.U^{-}\right)$}

Following Dubois and Prade's possibilistic approach of decision making under qualitative uncertainty, a one stage decision can be seen as a possibility distribution over a finite set of outcomes also called a (simple) possibilistic lottery [3]. Since we consider a finite setting, we shall write $L=\left\langle\lambda_{1} / x_{1}, \ldots, \lambda_{n} / x_{n}\right\rangle$ s.t. $\lambda_{i}=\pi_{f}\left(x_{i}\right)$ is the possibility that decision $f$ leads to outcome $x_{i}$; this possibility degree can also be denoted by $L\left[x_{i}\right]$. We denote $\mathcal{L}$ the set of all simple possibilistic lotteries.

In this framework, a decision problem is thus fully specified by a set $\Delta$ of possibilistic lotteries on a set of consequences $X$ and a utility function $u: X \mapsto$ $[0,1]$. Under the assumption that the utility scale and the possibility scale are commensurate and purely ordinal, Dubois and Prade have proposed the following qualitative degrees for evaluating any simple lottery $L=\left\langle\lambda_{1} / x_{1}, \ldots, \lambda_{n} / x_{n}\right\rangle$ :

$$
\begin{array}{ll}
\text { Optimistic utility }\left(U^{+}\right)[3,15,16]: & U^{+}(L)=\max _{x_{i} \in X} \min \left(\lambda_{i}, u\left(x_{i}\right)\right) \\
\text { Pessimistic utility }\left(U^{-}\right)[3,14]: & U^{-}(L)=\min _{x_{i} \in X} \max \left(\left(1-\lambda_{i}\right), u\left(x_{i}\right)\right)
\end{array}
$$

The value $U^{-}(L)$ is high only if $L$ gives good consequences in every "rather plausible" state. This criterion generalizes the Wald criterion, which estimates

\footnotetext{
${ }^{1}$ Proofs relative to this paper are omitted for lack of space; they are available on ftp://ftp.irit.fr/IRIT/ADRIA/PapersFargier/ipmu14.pdf
} 
the utility of an act by its worst possible consequence. $U^{-}(L)$ is thus "pessimistic" or "cautious". On the other hand, $U^{+}(L)$ is a mild version of the maximax criterion which is "optimistic", or "adventurous": act $L$ is good as soon as it is totally plausible that it gives a good consequence.

\subsection{Multi-criteria decision making (MCDM) using $\mathrm{Agg}^{+}$and $\mathrm{Agg}^{-}$}

The previous setting assumes a clear ranking of $X$ by a single preference criterion, hence the use of a single utility function $u$. When several criteria, say a set $C=\left\{c_{1} \ldots c_{p}\right\}$ of $p$ criteria, have to be taken into account, $u$ shall be replaced by a vector $\boldsymbol{u}=\left\langle u_{1}, \ldots, u_{p}\right\rangle$ of utility functions $u_{j}: X \mapsto[0,1]$ and the global (qualitative) utility of each consequence $x \in X$ can be evaluated either in a conjunctive, cautious, way according to the Wald aggregation $\left(\mathrm{Agg}^{-}(x)=\min _{j=1, p} u_{j}(x)\right)$, or in an disjunctive way according to its max-oriented counterpart $\left(\mathrm{Agg}^{+}(x)=\max _{j=1, p} u_{j}(x)\right)$. When the criteria are not equally important, a weight $w_{j} \in[0,1]$ can be associated to each $c_{j}$. Hence the following definitions relative to multi-criteria utilities [2]:

$$
\begin{gathered}
\operatorname{Agg}^{+}(x)=\max _{j=1, p} \min \left(w_{j}, u_{j}(x)\right) . \\
\operatorname{Agg}^{-}(x)=\min _{j=1, p} \max \left(\left(1-w_{j}\right), u_{j}(x)\right) .
\end{gathered}
$$

These utilities are particular cases of the Sugeno integral $[1,8,13]$ :

$$
\operatorname{Agg}_{\gamma, u}(L)=\max _{\lambda \in[0,1]} \min \left(\lambda, \gamma\left(F_{\lambda}\right)\right)
$$

where $F_{\lambda}=\left\{c_{j} \in C, u_{j}(x) \geq \lambda\right\}, \gamma$ is a monotonic set-function that reflects the importance of criteria's set. $\mathrm{Agg}^{+}$is recovered when $\gamma$ is the possibility measure based on the weight distribution $\left(\gamma(E)=\max _{c_{j} \in E} w_{j}\right)$, and $A g g^{-}$is recovered when $\gamma$ corresponds to necessity measure $\left(\gamma(E)=\min _{c_{j} \notin E}\left(1-w_{j}\right)\right)$.

\section{Multi-criteria decision making under possibilistic uncertainty}

Let us now study possibilistic decision making in a multi-criteria context. Given a set $X$ of consequences, a set $C$ of independent criteria we define a multi-criteria decision problem under possibilistic uncertainty as triplet $\langle\Delta, \boldsymbol{w}, \boldsymbol{u}\rangle^{2}$ where:

$-\Delta$ is a set of possibilistic lotteries;

\footnotetext{
${ }^{2}$ Classical problems of decision under possibilistic uncertainty are recovered when $|C|=1$; Classical MCDM problems are recovered when all the lotteries in $\Delta$ associate possibility 1 to some $x_{i}$ and possibility 0 to all the other elements of $X: \Delta$ is identified to $X$, i.e. is a set of "alternatives" for the MCDM decision problem.
} 
- $\boldsymbol{w} \in[0,1]^{p}$ is a weighting vector: $w_{j}$ denotes the weight of criterion $c_{j}$;

$-\boldsymbol{u}=\left\langle u_{1}, \ldots, u_{p}\right\rangle$ is a vector of $p$ utility functions on $X: u_{j}\left(x_{i}\right) \in[0,1]$ is the utility of $x_{i}$ according to criterion $c_{j}$;

Our aim consists in comparing lotteries according to decision maker's preferences relative to their different consequences (captured by the utility functions) and the importance of the criteria (captured by the weighting vector). To do this, we can proceed in two different ways namely ex-ante or ex-post:

- The ex-ante aggregation consists in first determining the aggregated utilities $\left(\mathrm{Agg}^{+}\right.$or $\left.\mathrm{Agg}^{-}\right)$relative to each possible consequence $x_{i}$ of $L$ and then combine them with the possibility degrees.

- The ex-post aggregation consists in computing the (optimistic or pessimistic) utilities relative to each criterion $c_{j}$, and then perform the aggregation $\mathrm{Agg}^{+}$ or $\left.A g g^{-}\right)$using the criteria's weights.

We borrow this terminology from economics and social welfare economics, were agents play the role played by criteria in the present context (see e.g. [7, 10]). Setting the problem in a probabilistic context, these works have shown that the two approaches can lead to different results (the so-called "timing effect") coincide iff the collective utility is affine. As a matter of fact, it is easy to show that the expected utility of the weighted sum is the sum of the expected utilities.

Let us go back to possibilistic framework. The decision maker's attitude with respect to uncertainty can be either optimistic $\left(U^{+}\right)$or pessimistic $\left(U^{-}\right)$and her attitude with respect to criteria can be either conjunctive $\left(\mathrm{Agg}^{+}\right)$or disjunctive $\left(\mathrm{Agg}^{-}\right)$, hence the definition of four approaches of MCDM under uncertainty, namely $U^{++}, U^{+-}, U^{-+}$and $U^{--}$; the first (resp. the second) indices denoting the attitude of the decision maker w.r.t. uncertainty (resp. criteria).

Each of these utilities can be computed either ex-ante or ex-post. Hence the definition of eight utilities:

Definition 1. Given a possibilistic lottery $L$ on $X$, a set of criteria $C$ defining a vector of utility functions $\boldsymbol{u}$ and weighting vector $\boldsymbol{w}$, let:

$$
\begin{gathered}
U_{\text {ante }}^{++}(L)=\max _{x_{i} \in X} \min \left(L\left[x_{i}\right], \max _{c_{j} \in C} \min \left(u_{j}\left(x_{i}\right), w_{j}\right)\right) . \\
U_{\text {ante }}^{--}(L)=\min _{x_{i} \in X} \max \left(\left(1-L\left[x_{i}\right]\right), \min _{c_{j} \in C} \max \left(u_{j}\left(x_{i}\right),\left(1-w_{j}\right)\right)\right) . \\
U_{\text {ante }}^{+-}(L)=\max _{x_{i} \in X} \min \left(L\left[x_{i}\right], \min _{c_{j} \in C} \max \left(u_{j}\left(x_{i}\right),\left(1-w_{j}\right)\right)\right) . \\
U_{\text {ante }}^{-+}(L)=\min _{x_{i} \in X} \max \left(\left(1-L\left[x_{i}\right]\right), \max _{c_{j} \in C} \min \left(u_{j}\left(x_{i}\right), w_{j}\right)\right) . \\
U_{\text {post }}^{++}(L)=\max _{c_{j} \in C} \min \left(w_{j}, \max _{x_{i} \in X} \min \left(u_{j}\left(x_{i}\right), L\left[x_{i}\right]\right)\right) . \\
U_{\text {post }}^{--}(L)=\min _{c_{j} \in C} \max \left(\left(1-w_{j}\right), \min _{x_{i} \in X} \max \left(u_{j}\left(x_{i}\right),\left(1-L\left[x_{i}\right]\right)\right)\right) . \\
U_{\text {post }}^{+-}(L)=\min _{c_{j} \in C} \max \left(\left(1-w_{j}\right), \max _{x_{i} \in X} \min \left(u_{j}\left(x_{i}\right), L\left[x_{i}\right]\right)\right) .
\end{gathered}
$$




$$
U_{\text {post }}^{-+}(L)=\max _{c_{j} \in C} \min \left(w_{j}, \min _{x_{i} \in X} \max \left(u_{j}\left(x_{i}\right),\left(1-L\left[x_{i}\right]\right)\right)\right) .
$$

Interestingly, the optimistic aggregations are related to their pessimistic counterparts by duality as stated by the following proposition.

Proposition 1. Let $P=\langle\Delta, \boldsymbol{w}, \boldsymbol{u}\rangle$ be a qualitative decision problem, let $P^{\tau}=$ $\left\langle\Delta, \boldsymbol{w}, \boldsymbol{u}^{\tau}\right\rangle$ be the inverse problem, i.e. the problem such that for any $x_{i} \in X, c_{j} \in$ $C, u_{j}^{\tau}\left(x_{i}\right)=1-u_{j}\left(x_{i}\right)$. Then, for any $L \in \Delta$ :

$$
\begin{array}{ll}
U_{\text {ante }}^{++}(L)=1-U_{\text {ante }}^{\tau--}(L) & U_{\text {post }}^{++}(L)=1-U_{\text {post }}^{\tau--}(L) \\
U_{\text {ante }}^{--}(L)=1-U_{\text {ante }}^{\tau++}(L) & U_{\text {post }}^{--}(L)=1-U_{\text {post }}^{\tau++}(L) \\
U_{\text {ante }}^{+-}(L)=1-U_{\text {ante }}^{\tau-+}(L) & U_{\text {post }}^{+-}(L)=1-U_{\text {post }}^{\tau-+}(L) \\
U_{\text {ante }}^{-+}(L)=1-U_{\text {ante }}^{\tau+-}(L) & U_{\text {post }}^{-+}(L)=1-U_{\text {post }}^{\tau+-}(L)
\end{array}
$$

As previously said the ex-ante and the ex-post approaches coincide in the probabilistic case. Likewise, the following Proposition 2 shows that when the decision maker attitude is homogeneous, i.e. either fully min-oriented or fully maxoriented, the ex-ante and the ex-post possibilistic aggregations provide the same result.

Proposition 2. For any $L \in \mathcal{L}, U_{\text {ante }}^{++}(L)=U_{\text {post }}^{++}(L)$ and $U_{\text {ante }}^{--}(L)=U_{\text {post }}^{--}(L)$. Hence, for any multi-criteria decision problem under possibilistic uncertainty, $U_{\text {ante }}^{++}\left(\right.$resp. $\left.U_{\text {ante }}^{--}\right)$is equal to $U_{\text {post }}^{++}\left(\right.$resp. $\left.U_{\text {post }}^{--}\right)$. Such an equivalence between the ex-ante and ex-post does not hold for $U^{+-}$nor for $U^{-+}$, as shown by the following counter-example.

Counter-example 1 Consider a set $C$ of two equally important criteria $c_{1}$ and $c_{2}$, and a lottery $L$ (cf. Figure 1) leading to two equi-possible consequences $x_{1}$ and $x_{2}$ such that $x_{1}$ is good for $c_{1}$ and bad for $c_{2}$, and $x_{2}$ is bad for $c_{1}$ and good for $c_{2}$; i.e. $L\left[x_{1}\right]=L\left[x_{2}\right]=1, w_{1}=w_{2}=1, u_{1}\left(x_{1}\right)=u_{2}\left(x_{2}\right)=1$ and $u_{2}\left(x_{1}\right)=u_{1}\left(x_{2}\right)=0$.

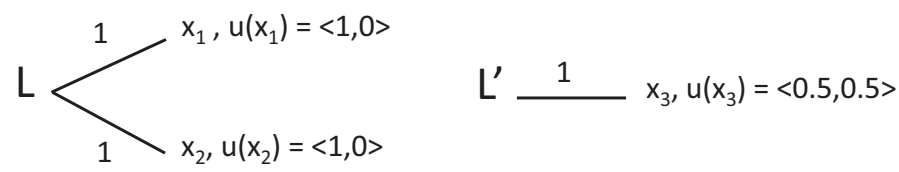

Fig. 1. Lotteries $L$ and $L^{\prime}$ relative to counter-example 1

We can check that $U_{\text {ante }}^{+-}(L)=0 \neq U_{\text {post }}^{+-}(L)=1$ :

$$
\begin{aligned}
& U_{\text {ante }}^{+-}(L)=\max \left(\min \left(L\left[x_{1}\right], \min \left(\max \left(u_{1}\left(x_{1}\right),\left(1-w_{1}\right)\right), \max \left(u_{2}\left(x_{1}\right),\left(1-w_{2}\right)\right)\right)\right),\right. \\
& \left.\min \left(L\left[x_{2}\right], \min \left(\max \left(u_{1}\left(x_{2}\right),\left(1-w_{1}\right)\right), \max \left(u_{2}\left(x_{2}\right),\left(1-w_{2}\right)\right)\right)\right)\right) . \\
& =\max (\min (1, \min (\max (1,(1-1)), \max (0,(1-1)))) \text {, } \\
& =0 \text {. }
\end{aligned}
$$




$$
\begin{aligned}
U_{\text {post }}^{+-}(L)= & \min \left(\max \left(\left(1-w_{1}\right), \max \left(\min \left(u_{1}\left(x_{1}\right), L\left[x_{1}\right]\right), \min \left(u_{1}\left(x_{2}\right), L\left[x_{2}\right]\right)\right)\right),\right. \\
& \left.\quad \max \left(\left(1-w_{2}\right), \max \left(\min \left(u_{2}\left(x_{1}\right), L\left[x_{1}\right]\right), \min \left(u_{2}\left(x_{2}\right), L\left[x_{2}\right]\right)\right)\right)\right) . \\
= & \min (\max ((1-1), \max (\min (1,1), \min (0,1))), \\
=1 . & \max ((1-1), \max (\min (0,1), \min (1,1))))
\end{aligned}
$$

The ex-ante and ex-post approaches may lead to different rankings of lotteries. Consider for instance, a lottery $L^{\prime}$ leading to the consequence $x_{3}$ for sure, i.e. $L^{\prime}\left[x_{3}\right]=1$ and $L^{\prime}\left[x_{i}\right]=0, \forall i \neq x_{3}$ (such a lottery is called a constant lottery), with $u_{1}\left(x_{3}\right)=u_{2}\left(x_{3}\right)=0.5$. It is easy to check that $U_{\text {ante }}^{+-}\left(L^{\prime}\right)=U_{\text {post }}^{+-}\left(L^{\prime}\right)=0.5$ i.e. $U_{\text {ante }}^{+-}(L)<U_{\text {ante }}^{+-}\left(L^{\prime}\right)$ while $U_{\text {post }}^{+-}(L)>U_{\text {post }}^{+-}\left(L^{\prime}\right)$.

Using the same lotteries $L$ and $L^{\prime}$, we can show that:

$U_{\text {ante }}^{-+}(L)=1 \neq U_{\text {post }}^{-+}(L)=0$ and that $U_{\text {ante }}^{-+}\left(L^{\prime}\right)=U_{\text {post }}^{-+}\left(L^{\prime}\right)=0.5$; then $U_{\text {post }}^{-+}\left(L^{\prime}\right)>U_{\text {post }}^{-+}(L)$ while $U_{\text {ante }}^{-+}\left(L^{\prime}\right)<U_{\text {ante }}^{-+}(L)$ : like $U^{+-}, U^{-+}$are subject to the timing effect.

In summary, $U^{-+}$and $U^{+-}$suffer from the timing effect, contrary to $U^{--}$and $U^{++}$.

\section{Multi-criteria sequential decision making under possibilistic uncertainty}

Possibilistic sequential decision making relies on possibilistic compound lotteries[3], that is a possibility distributions over (simple or compound) lotteries. Compound lotteries indeed allow the representation of decision policies or "strategies", that associate a decision to each decision point: the execution of the decision may lead to several more or less possible situations, where new decisions are to be made, etc. For instance, in a two stages decision problem, a first decision is made and executed; then, depending on the observed situation, a new, one stage, decision is to be made, that lead to the final consequences. The decisions at the final stage are simple lotteries, and the decision made at the first stage branches on each of them. The global strategy thus defines to a compound lottery .

To evaluate a strategy by $U^{+}, U^{-}$or, in the case of MCDM under uncertainty by any of the eight aggregated utility proposed in Section 3, the idea is to "reduce" its compound lottery into an equivalent simple one. Consider a compound lottery $L=\left\langle\lambda_{1} / L_{1}, \ldots, \lambda_{m} / L_{m}\right\rangle$; the possibility of getting consequence $x_{i} \in X$ from one of its sub lotteries $L_{k}$ is $\pi_{k, i}=\min \left(\lambda_{k}, L_{k}\left[x_{i}\right]\right)$ (for the shake of simplicity, suppose that $L_{k}^{\prime}$ are simple lotteries; the principle trivially extends to the general case). Hence, the possibility of getting $x_{i}$ from $L$ is the $\max$, over all the $L_{k}$ 's, of $\pi_{k, i}$. Thus, [3] have proposed to reduce a compound lottery $\left\langle\lambda_{1} / L_{1}, \ldots, \lambda_{m} / L_{m}\right\rangle$ into a simple lottery, denoted by Reduction $\left(\left\langle\lambda_{1} / L_{1}, \ldots, \lambda_{m} / L_{m}\right\rangle\right)$, that is considered as equivalent to the compound one: Reduction $\left(\left\langle\lambda_{1} / L_{1}, \ldots, \lambda_{m} / L_{k}\right\rangle\right)$ is the simple lottery that associate to each $x_{i}$ the possibility degree $\max _{k=1 . . m} \min \left(\lambda_{k}, L_{k}\left[x_{i}\right]\right.$ ) (with $L\left[x_{i}\right]=0$ when none of the $L_{k}$ 's give a positive possibility degree to consequence $x_{i}$ ). See Figure 2 for an example. 


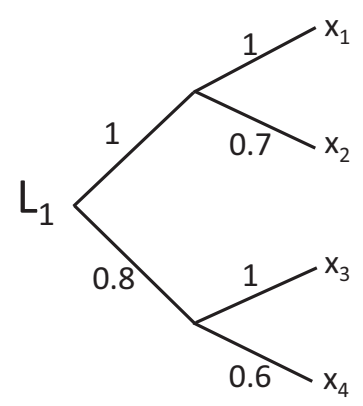

(a)

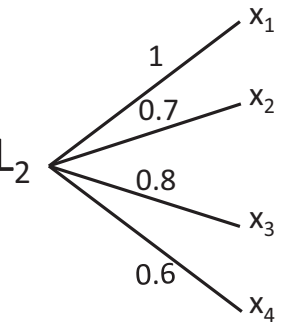

(b)

Fig. 2. A compound lottery $L_{1}$ (a) and its reduction $L_{2}$ (b)

From a practical point of view, sequential decision problems are generally stated through the use of compact representation formalisms, such as possibilistic decision trees [4], possibilistic influence diagrams [5,6] or possibilistic Markov decision processes $[11,12]$. The set of potential strategies to compare, $\Delta$, is generally exponential w.r.t. the input size. So, an explicit evaluation of each strategy in $\Delta$ is not realistic. Such problems can nevertheless be solved efficiently, without an explicit evaluation of the strategies, by Dynamic Programming algorithms as soon as the decision rule leads to transitive preferences and satisfies the principle of weak monotonicity. Formally, for any decision rule $O$ (e.g. $U^{+}, U^{-}$or even any of the decision rules proposed in the previous Section) over possibilistic lotteries, $\geq_{O}$ is said to be weakly monotonic iff whatever $L, L^{\prime}$ and $L^{\prime \prime}$ and whatever $(\alpha, \beta)$ such that $\max (\alpha, \beta)=1$ :

$$
L \succeq_{O} L^{\prime} \Rightarrow\left\langle\alpha / L, \beta / L^{\prime \prime}\right\rangle \succeq_{O}\left\langle\alpha / L^{\prime}, \beta / L^{\prime \prime}\right\rangle
$$

Such property ensures that each sub-strategy of an optimal strategy is optimal in its sub-problem. This allows Dynamic Programming algorithms to build optimal strategies in an incremental way (e.g. in decision tree, from the last decision to the root of the tree).

$[5,4]$ have shown that $U^{+}$and $U^{-}$are monotonic. Let us now study whether it is also the case for the ex-ante and ex-post rules proposed in the previous Section. The ex-ante approaches are the easiest to handle: once the vectors of utilities have been aggregated according to $\mathrm{Agg}^{-}$(resp. $\mathrm{Agg}^{+}$), these approaches collapse with the classical $U^{+}$and $U^{-}$approaches. It is then easy to show that:

Proposition 3. $U_{\text {ante }}^{++}, U_{\text {ante }}^{--}, U_{\text {ante }}^{+-}$and $U_{\text {ante }}^{-+}$satisfy the weak monotonicity.

Concerning $U_{\text {post }}^{++}$and $U_{\text {post }}^{--}$, recall that the full optimistic and full pessimistic expost utilities are equivalent to their ex-ante counterparts thanks to Proposition 2. This allows us to show that: 
Proposition 4. $U_{\text {post }}^{--}$and $U_{\text {post }}^{++}$satisfy the weak monotonicity.

It follows from Propositions 3 and 4 that when the decision is based either on an ex-ante approach, or on $U_{\text {post }}^{++}$or $U_{\text {post }}^{--}$, the algorithms proposed by Sabbadin et al. $[12,5]$ can be used on multi-criteria possibilistic decision trees and influence diagrams after their transformation into single-criterion problems: it is enough to aggregate the vectors of utilities leading to the consequences $x$ into single utilities using $\mathrm{Agg}^{+}$(for $U_{\text {ante }}^{++}, U_{\text {ante }}^{-+}, U_{\text {post }}^{++}$) or $\mathrm{Agg}^{-}$(for $U_{\text {ante }}^{--}, U_{\text {ante }}^{+-}, U_{\text {post }}^{--}$) to get an equivalent single criterion problem where the criterion to optimize is simply $U^{+}$(for $U_{\text {ante }}^{++}, U_{\text {ante }}^{+-}, U_{\text {post }}^{++}$) or $U^{-}$(for $\left.U_{\text {ante }}^{--}, U_{\text {ante }}^{-+}, U_{\text {post }}^{--}\right)$.

Such approach cannot be applied when optimizing $U_{\text {post }}^{-+}$or $U_{\text {post }}^{+-}$. First because $U_{\text {post }}^{+-}(L) \neq U_{\text {ante }}^{+-}(L)$ and $U_{\text {post }}^{-+}(L) \neq U_{\text {ante }}^{+-}(L)$, i.e. the reduction of the problem to the optimization w.r.t. $U^{+}$(resp. $U^{-}$) of a single criterion problem obtained by aggregating the utilities with $\mathrm{Agg}^{-}\left(\mathrm{resp} . \mathrm{Agg}^{+}\right.$) can lead to a wrong result. Worst, it is not even possible to apply Dynamic Programming, since $U_{\text {post }}^{-+}$and $U_{\text {post }}^{+-}$do not satisfy the weak monotonicity property, as shown by the following counter-example:

Counter-example 2 Let $X=\left\{x_{1}, x_{2}, x_{3}\right\}$ and consider two equally important criteria $c_{1}$ and $c_{2}\left(w_{1}=w_{2}=1\right)$ with : $u_{1}\left(x_{1}\right)=1, u_{1}\left(x_{2}\right)=0.8$, $u_{1}\left(x_{3}\right)=0.5 ; u_{2}\left(x_{1}\right)=0.6, u_{2}\left(x_{2}\right)=0.8, u_{2}\left(x_{3}\right)=0.8$. Consider the lotteries $L=\left\langle 1 / x_{1}, 0 / x_{2}, 0 / x_{3}\right\rangle, L^{\prime}=\left\langle 0 / x_{1}, 1 / x_{2}, 0 / x_{3}\right\rangle$ and $L^{\prime \prime}=\left\langle 0 / x_{1}, 0 / x_{2}, 1 / x_{3}\right\rangle$ : $L$ gives consequence $x_{1}$ for sure, $L^{\prime}$ gives consequence $x_{2}$ for sure and $L^{\prime \prime}$ gives consequence $x_{3}$ for sure. It holds that:

$$
\begin{aligned}
& U_{\text {post }}^{-+}(L)=A g g^{-}\left(x_{1}\right)=\max (1,0.6)=1 \\
& U_{\text {post }}^{-+}\left(L^{\prime}\right)=A g g^{-}\left(x_{2}\right)=\max (0.8,0.8)=0.8 .
\end{aligned}
$$

Hence $L>_{U_{\text {post }}^{-+}} L^{\prime}$ with respect to the $U_{\text {post }}^{-+}$rule.

Consider now the compound lotteries $L_{1}=\left\langle 1 / L, 1 / L^{\prime \prime}\right\rangle$ and $L_{2}=\left\langle 1 / L^{\prime}, 1 / L^{\prime \prime}\right\rangle$. If the weak monotonicity principle were satisfied, we would get: $L_{1}>_{U_{\text {post }}^{-+}} L_{2}$. Since: $\operatorname{Reduction}\left(\left\langle 1 / L, 1 / L^{\prime \prime}\right\rangle\right)=\left\langle 1 / x_{1}, 0 / x_{2}, 1 / x_{3}\right\rangle$ and Reduction $\left(\left\langle 1 / L^{\prime}, 1 / L^{\prime \prime}\right\rangle\right)=$ $\left\langle 0 / x_{1}, 1 / x_{2}, 1 / x_{3}\right\rangle$. We have:

$U_{\text {post }}^{-+}\left(L_{1}\right)=U_{\text {post }}^{-+}\left(\operatorname{Reduction}\left(\left\langle 1 / L, 1 / L^{\prime \prime}\right\rangle\right)\right)=0.6$.

$U_{\text {post }}^{-+}\left(L_{2}\right)=U_{\text {post }}^{-+}\left(\operatorname{Reduction}\left(\left\langle 1 / L^{\prime}, 1 / L^{\prime \prime}\right\rangle\right)\right)=0.8$.

Hence, $L_{1}<_{U_{\text {post }}^{-+}}^{-+} L_{2}$ while $L>_{U_{\text {post }}^{-+}} L^{\prime}$, which contradicts weak monotonicity.

Using the fact that $U_{\text {post }}^{+-}=1-U_{\text {post }}^{\tau-+}$, this counter-example is modified to show that also $U_{\text {post }}^{+-}$does not satisfy the monotonicity principle. Consider two equally important criteria, $c_{1}^{\tau}$ and $c_{2}^{\tau}$ with $w_{1}=w_{2}=1$ with: $u_{1}^{\tau}\left(x_{1}\right)=0$, $u_{1}^{\tau}\left(x_{2}\right)=0.2, u_{1}^{\tau}\left(x_{3}\right)=0.5 ; u_{2}^{\tau}\left(x_{1}\right)=0.4, u_{2}^{\tau}\left(x_{2}\right)=0.2, u_{2}^{\tau}\left(x_{3}\right)=0.2$. Consider now the same lotteries $L, L^{\prime}$ and $L^{\prime \prime}$ presented above. It holds that:

$U_{\text {post }}^{+-}(L)=A g^{-}\left(x_{1}\right)=0<U_{\text {post }}^{+-}\left(L^{\prime}\right)=\operatorname{Agg}^{-}\left(x_{2}\right)=0.2$, while $U_{\text {post }}^{+-}\left(\operatorname{Reduction}\left(\left\langle 1 / L, 1 / L^{\prime \prime}\right\rangle\right)\right)=0.4>U_{\text {post }}^{+-}\left(\operatorname{Reduction}\left(\left\langle 1 / L^{\prime}, 1 / L^{\prime \prime}\right\rangle\right)\right)=0.2$.

The lack of monotonicity of $U_{\text {post }}^{-+}$is not as dramatic as it may seem. When optimizing $U_{\text {post }}^{-+}(L)$, the decision maker is looking for a strategy that is good 
w.r.t. $U^{-}$for at least one criterion. This means that if it is possible to get for each criterion $c_{j}$ a strategy that optimizes $U^{-}$according to this criterion (and this can be done by Dynamic Programming, since $U^{-}$do satisfy the principle of monotonicity), the one with the higher $U^{-}$is optimal w.r.t. $U_{\text {post }}^{-+}(L)$. Formally:

Proposition 5. $U_{\text {post }}^{-+}(L)=\max _{j=1, p} \min \left(w_{j}, U_{j}^{-}(L)\right)$

where $U_{j}^{-}(L)=\min _{x_{i} \in X} \max \left(\left(1-L\left[x_{i}\right]\right), u_{j}\left(x_{i}\right)\right)$ is the pessimistic utility of $L$ according to the sole criterion $j$.

Proposition 6. Let $\mathcal{L}$ be the set of lotteries that can be built on $X$ and let:

$$
\begin{aligned}
& -\Delta^{*}=\left\{L_{1}^{*}, \ldots, L_{p}^{*}\right\} \text { s.t. } \forall L \in \mathcal{L}, j \in 1 \ldots p, U_{j}^{-}\left(L_{j}^{*}\right) \geq U_{j}^{-}(L) ; \\
& -L^{*} \in \Delta^{*} \text { s.t. } \forall L_{j}^{*} \in \Delta^{*}: \max _{j=1, p} \min \left(w_{j}, U_{j}^{-}\left(L^{*}\right)\right) \geq \max _{j=1, p} \min \left(w_{j}, U_{j}^{-}\left(L_{i}^{*}\right)\right) .
\end{aligned}
$$

It holds that, for any $L \in \mathcal{L}, U_{\text {post }}^{-+}\left(L^{*}\right) \geq U_{\text {post }}^{-+}(L)$.

Hence, it is enough to optimize w.r.t. each criterion separately and to compare the results to get an optimal strategy w.r.t. $U_{\text {post }}^{-+}(L)$.

Let us finally study $U_{\text {post }}^{+-}$; an analog of Proposition 6 exists:

Proposition 7. $U_{\text {post }}^{+-}(L)=\min _{j=1, p} \max \left(\left(1-w_{j}\right), U_{j}^{+}(L)\right)$ where $U_{j}^{+}(L)=\max _{x_{i} \in X} \min \left(L\left[x_{i}\right], u_{j}\left(x_{i}\right)\right)$ is the optimistic utility of $L$ according to the sole criterion $j$.

But this proposition is helpless, since the lottery $L$ maximizing this quantity is not necessarily among those maximizing the $U_{j}^{+}$'s: one lottery optimal for $U_{1}^{+}$ w.r.t. criterion $c_{1}$ can be very bad for $U_{2}^{+}$and thus bad for $U_{\text {post }}^{+-}$.

\section{Conclusion}

This paper has provided a first decision theoretical approach for evaluating multicriteria decision problems under possibilistic uncertainty. The combination of the multi-criteria dimension, namely the conjunctive aggregation with a weighted $\min \left(A g g^{-}\right)$or the disjunctive aggregation with a weighted $\max \left(A g g^{-}\right)$and the decision maker's attitude with respect to uncertainty (i.e. optimistic utility $U^{+}$or pessimistic utility $U^{-}$) leads to four approaches of MCDM under possibilistic uncertainty. Considering that each of these utilities can be computed either ex-ante or ex-post, we have proposed the definition of eight aggregations, that eventually reduce to six: $U_{\text {ante }}^{++}$(resp. $U_{\text {ante }}^{--}$) has been shown to coincide with $U_{\text {post }}^{++}\left(\right.$resp. $\left.U_{\text {post }}^{--}\right)$; such a coincidence does not happen for $U^{+-}$and $U^{-+}$, that suffer from timing effect.

Then, in order to use these decision rules in sequential decision problems, we have proven that all ex-ante utilities (i.e. $U_{\text {ante }}^{++}, U_{\text {ante }}^{--}, U_{\text {ante }}^{+-}, U_{\text {ante }}^{-+}$) satisfy the weak monotonicity while for the ex-post utilities, only $U_{\text {post }}^{++}$and $U_{\text {post }}^{--}$satisfy this property. This result means that Dynamic Programming algorithms can 
be used to compute strategies that are optimal w.r.t. the rules . We have also shown that the optimization of $U_{\text {post }}^{+-}$can be handled thanks to a call of a series of optimization of pessimistic utilities (one for each criterion). The question of the optimization of $U_{\text {post }}^{-+}$still remains open.

This preliminary work call for several developments. First of all we intend, as future work, to propose and test suitable algorithms to solve sequential qualitative multi-criteria decision problems, e.g. influence diagrams and decision trees. From a more theoretical point of view we have to propose a general axiomatic characterization of our six decision rules. Finally, considering that the possibilistic aggregations used here are basically specializations of the Sugeno integral, we aim at generalizing the study of MCDM decision making under uncertainty through the development of double Sugeno Integrals.

\section{References}

1. D. Dubois, J.L. Marichal, H. Prade, M. Roubens, and R. Sabbadin. The use of the discrete sugeno integral in decision-making: A survey. International Journal of Uncertainty, Fuzziness and Knowledge-Based Systems, 9(5):539-561, 2001.

2. D. Dubois and H. Prade. Weighted minimum and maximum operations in fuzzy set theory. journal of Information Sciences, 39:205-210, 1986.

3. D. Dubois and H. Prade. Possibility theory as a basis for qualitative decision theory. In Proceedings of IJCAI, pages 1924-1930, 1995.

4. H. Fargier, N. Ben Amor, and W. Guezguez. On the complexity of decision making in possibilistic decision trees. In Conference on UAI, pages 203-210, 2011.

5. L. Garcias and R. Sabbadin. Possibilistic influence diagrams. In Proceedings of ECAI, pages 372-376, 2006.

6. W. Guezguez, N. Ben Amor, and K. Mellouli. Qualitative possibilistic influence diagrams based on qualitative possibilistic utilities. EJOR, 195:223-238, 2009.

7. J.C. Harsanyi. Cardinal welfare, individualistic ethics, and interpersonal comparisons of utility. Journal of Political Economy, 63(4):309-321, 1955.

8. J.L. Marichal. An axiomatic approach of the discrete sugeno integral as a tool to aggregate interacting criteria in a qualitative framework. IEEE T. on Fuzzy Systems, 9(1):164-172, 2001.

9. O. Morgenstern and J.V. Neumann. Theory of Games and Economic Behavior. Princeton University Press, second edition, 1947.

10. R.B. Myerson. Utilitarianism, egalitarianism, and the timing effect in social choice problems. Econometrica, 49(4):883-97, 1981.

11. R. Sabbadin. Empirical comparison of probabilistic and possibilistic markov decision processes algorithms. In Proceedings of European Conference on Artificial Intelligence, pages 586-590, 2000.

12. R. Sabbadin. Possibilistic markov decision processes. Engineering Applications of Artificial Intelligence, 14:287-300, 2001.

13. M. Sugeno. Theory of fuzzy integrals and its applications. PhD thesis, Tokyo Institute of Technology, 1974.

14. T. Whalen. Decision making under uncertainty with various assumptions about available information. IEEE T. on SMC, 14:888-900, 1984.

15. R. Yager. Possibilistic decision making. IEEE T. on SMC, 9:388-392, 1979.

16. L.A. Zadeh. Fuzzy sets as a basis for a theory of possibility. Fuzzy Sets and Systems, 1:3-28, 1978. 


\section{Appendix: Proofs}

Proof (Proposition 1). The proofs relative to these results are quite similar, so we show that $U_{\text {post }}^{+-}(L)=1-U_{\text {post }}^{\tau-+}(L)$, (i.e. $1-U_{\text {post }}^{+-}(L)=U_{\text {post }}^{\tau-+}(L)$ ) and we can apply the same principle to prove other utilities.

$$
\begin{aligned}
& 1-U_{\text {post }}^{+-}(L)=1-\left[\min _{c_{j} \in C} \max \left(\left(1-w_{j}\right), \max _{x_{i} \in X} \min \left(u_{j}\left(x_{i}\right), L\left[x_{i}\right]\right)\right)\right] \\
& =\max _{c_{j} \in C} 1-\left[\max \left(\left(1-w_{j}\right), \max _{x_{i} \in X} \min \left(u_{j}\left(x_{i}\right), L\left[x_{i}\right]\right)\right)\right] \\
& =\max _{c_{j} \in C} \min 1-\left[\left(\left(1-w_{j}\right), \max _{x_{i} \in X} \min \left(u_{j}\left(x_{i}\right), L\left[x_{i}\right]\right)\right)\right] \\
& =\max _{c_{j} \in C} \min \left(w_{j}, 1-\left[\max _{x_{i} \in X} \min \left(u_{j}\left(x_{i}\right), L\left[x_{i}\right]\right)\right]\right) \\
& =\max _{c_{j} \in C} \min \left(w_{j}, \min _{x_{i} \in X} 1-\left[\min \left(u_{j}\left(x_{i}\right), L\left[x_{i}\right]\right)\right]\right) \\
& =\max _{c_{j} \in C} \min \left(w_{j}, \min _{x_{i} \in X} \max 1-\left[\left(u_{j}\left(x_{i}\right), L\left[x_{i}\right]\right)\right]\right) \\
& =\max _{c_{j} \in C} \min \left(w_{j}, \min _{x_{i} \in X} \max \left(1-u_{j}\left(x_{i}\right),\left(1-L\left[x_{i}\right]\right)=\max _{c_{j} \in C} \min \left(w_{j}, \min _{x_{i} \in X} \max \left(u_{j}^{\tau}\left(x_{i}\right),(1-\right.\right.\right.\right. \\
& \left.L\left[x_{i}\right]\right) \\
& =U_{\text {post }}^{\tau-+}(L) .
\end{aligned}
$$

Proof (Propositon 2). In the following, we illustrate the proof relative to equivalence between $U_{\text {ante }}^{++}(L)$ and $U_{\text {post }}^{++}(L)$. The proof relative to $U^{--}$is similar by replacing max by min, $L\left[x_{i}\right]$ by $\left(1-L\left[x_{i}\right]\right)$ and $w_{j}$ by $\left(1-w_{j}\right)$.

$$
\begin{aligned}
& U_{\text {ante }}^{++}(L)=\max _{x_{i} \in X} \min \left(L\left[x_{i}\right], \max _{c_{j} \in C} \min \left(u_{j}\left(x_{i}\right), w_{j}\right)\right) \\
& =\max _{x_{i} \in X} \min \left(\max \left(\min \left(u_{1}\left(x_{i}\right), w_{1}\right), \min \left(u_{2}\left(x_{i}\right), w_{2}\right), \ldots, \min \left(u_{p}\left(x_{i}\right), w_{p}\right)\right), L\left[x_{i}\right]\right) \\
& =\max _{x_{i} \in X} \max \left(\min \left(\min \left(u_{1}\left(x_{i}\right), L\left[x_{i}\right]\right), w_{1}\right), \min \left(\min \left(u_{2}\left(x_{i}\right), L\left[x_{i}\right]\right), w_{2}\right), \ldots, \min \left(\min \left(u_{p}\left(x_{i}\right), L\left[x_{i}\right]\right), w_{p}\right)\right) \\
& =\max _{c_{j} \in C x_{i} \in X}\left(\min \left(\min \left(L\left[x_{i}\right], u_{j}\left(x_{i}\right)\right)\right), w_{j}\right) \\
& =\max _{c_{j} \in C} \max \left(\min \left(\min \left(L\left[x_{1}\right], u_{j}\left(x_{1}\right)\right), w_{j}\right), \min \left(\min \left(L\left[x_{2}\right], u_{j}\left(x_{2}\right)\right), w_{j}\right), \ldots, \min \left(\min \left(L\left[x_{n}\right], u_{j}\left(x_{n}\right)\right), w_{j}\right)\right) \\
& =\max _{c_{j} \in C} \min \left(\max \left(\min \left(L\left[x_{1}\right], u_{j}\left(x_{1}\right)\right), \min \left(L\left[x_{2}\right], u_{j}\left(x_{2}\right)\right), \ldots, \min \left(L\left[x_{n}\right], u_{j}\left(x_{n}\right)\right)\right), w_{j}\right) \\
& =\max _{c_{j} \in C} \min \left(\max _{x_{i} \in X}\left(\min \left(L\left[x_{i}\right], u_{j} x_{i}\right)\right), w_{j}\right) \\
& =U_{\text {post }}^{++}(L) .
\end{aligned}
$$

Proof (Propositon 3). To prove that $U_{\text {ante }}$ utilities satisfy the weak monotonicity property, we proceed by proving that $U_{\text {ante }}^{++}\left(\operatorname{resp} . U_{\text {ante }}^{--}\right)$and $U_{\text {ante }}^{+-}\left(\operatorname{resp} . U_{\text {ante }}^{-+}\right)$ are equivalent to their equivalent in context of mono-criterion decision making i.e. $U^{+}$(resp. $\left.U^{-}\right)$that are known as monotonic. While the principle is always the same, we will limit to the proof relative to the reduction of $U_{\text {ante }}^{++}$to $U^{+}$. $U^{++}\left(\left\langle\alpha \backslash L_{1}, \beta \backslash L_{2}, \ldots \gamma L_{m}\right\rangle\right)$.

$=U^{++}\left(\operatorname{red}\left(\left\langle\alpha \backslash L_{1}, \beta \backslash L_{2}, \ldots \gamma L_{m}\right\rangle\right)\right)$.

$=U^{+}\left(A g g^{+}\left(\operatorname{red}\left(\left\langle\alpha \backslash L_{1}, \beta \backslash L_{2}, \ldots \gamma L_{m}\right\rangle\right)\right)\right)$. 
$=U^{+}\left(\mathrm{Agg}^{+}\left(\max \left(\min \left(\alpha, L_{1}\left[x_{1}\right]\right), \min \left(\beta, L_{2}\left[x_{1}\right]\right), \ldots \min \left(\gamma, L_{m}\left[x_{1}\right]\right)\right) \backslash \boldsymbol{u}_{1}\right.\right.$, $\max \left(\min \left(\alpha, L_{1}\left[x_{2}\right]\right), \min \left(\beta, L_{2}\left[x_{2}\right]\right), \ldots \min \left(\gamma, L_{m}\left[x_{2}\right]\right)\right) \backslash \boldsymbol{u}_{\mathbf{2}}$,

$\ldots \max \left(\min \left(\alpha, L_{1}\left[x_{q}\right]\right), \min \left(\beta, L_{2}\left[x_{q}\right]\right), \ldots \min \left(\gamma, L_{m}\left[x_{q}\right]\right)\right) \backslash \boldsymbol{u}_{\boldsymbol{q}}$.

$=U^{+}\left(\max \left(\min \left(\alpha, L_{1}\left[x_{1}\right]\right), \min \left(\beta, L_{2}\left[x_{1}\right]\right), \ldots \min \left(\gamma, L_{m}\left[x_{1}\right]\right)\right) \backslash \max \left(\min \left(u_{11}, w_{1}\right), \min \left(u_{12}, w_{2}\right), \ldots \min \left(u_{1 p}, w_{p}\right)\right)\right)$, $\left.\max \left(\min \left(\alpha, L_{1}\left[x_{2}\right]\right), \min \left(\beta, L_{2}\left[x_{2}\right]\right), \ldots \min \left(\gamma, L_{m}\left[x_{2}\right]\right)\right) \backslash \max \left(\min \left(u_{21}, w_{1}\right), \min \left(u_{22}, w_{2}\right), \ldots \min \left(u_{2 p}, w_{p}\right)\right)\right)$, $\left.\ldots \max \left(\min \left(\alpha, L_{1}\left[x_{q}\right]\right), \min \left(\beta, L_{2}\left[x_{q}\right]\right), \ldots \min \left(\gamma, L_{m}\left[x_{q}\right]\right)\right) \backslash \max \left(\min \left(u_{q 1}, w_{1}\right), \min \left(u_{q 2}, w_{2}\right), \ldots \min \left(u_{q p}, w_{p}\right)\right)\right)$. $=U^{+}\left(\operatorname{red}\left(\alpha \backslash\left\langle L_{1}\left[x_{1}\right] \backslash \max \left(\min \left(u_{11}, w_{1}\right), \ldots \min \left(u_{1 p}, w_{p}\right)\right), \ldots L_{1}\left[x_{q}\right] \backslash \max \left(\min \left(u_{q 1}, w_{1}\right), \ldots \min \left(u_{q p}, w_{p}\right)\right)\right\rangle\right.\right.$, $\left.\left.\ldots \gamma \backslash\left\langle L_{m}\left[x_{1}\right] \backslash \max \left(\min \left(u_{11}, w_{1}\right), \ldots \min \left(u_{1 p}, w_{p}\right)\right), \ldots L_{m}\left[x_{q}\right] \backslash \max \left(\min \left(u_{q 1}, w_{1}\right), \ldots \min \left(u_{q p}, w_{p}\right)\right)\right\rangle.\right)\right)$ $=U^{+}\left(\operatorname{red}\left(\alpha \backslash \operatorname{Agg}^{+}\left(L_{1}\right), \beta \backslash A g g^{+}\left(L_{2}\right) \ldots \gamma \backslash A g g^{+}\left(L_{m}\right)\right)\right)$.

Proof (Proposition 4). We have proven that $U_{\text {ante }}^{++}$(resp. $U_{\text {ante }}^{--}$) equals to $U_{\text {post }}^{++}($resp. $U_{\text {post }}^{--}$), also we have shown that $U_{\text {ante }}^{++}$and $U_{\text {ante }}^{--}$are monotonic. So, we can conclude that $U_{\text {post }}^{++}$and $U_{\text {post }}^{++}$satisfy the weak monotonicity property.

Proof (Proposition 5). we have defined $U_{\text {post }}^{-+}(L)=\max _{j=1, p} \min \left(w_{j}, \min _{x_{i} \in X} \max ((1-\right.$ $\left.\left.\left.L\left[x_{i}\right]\right), u_{j}\left(x_{i}\right)\right)\right)$ and $U_{j}^{-}(L)=\min _{x_{i} \in X} \max \left(\left(1-L\left[x_{i}\right]\right), u_{j}\left(x_{i}\right)\right)$. So, $U_{\text {post }}^{-+}(L)$ can be expressed as follows: $U_{\text {post }}^{-+}(L)=\max _{j=1, p} \min \left(w_{j}, U_{j}^{-}(L)\right)$

Proof (Proposition 6). We suppose that $\Delta^{*}=\left\{L_{1}^{*}, \ldots, L_{p}^{*}\right\}$ and $\forall L \in \mathcal{L}, U_{j}^{-}\left(L_{k}^{*}\right) \geq$ $U_{j}^{-}\left(L_{k}\right)$, we have to prove that: for any $L \in \mathcal{L}, U_{\text {post }}^{-+}\left(L^{*}\right) \geq U_{\text {post }}^{-+}(L)$.

We start by verifying if $\min \left(w_{j}, U_{j}^{-}\left(L_{k}^{*}\right)\right) \geq \min \left(w_{j}, U_{j}^{-}\left(L_{k}\right)\right)$

- If $\left(w_{j} \leq U_{j}^{-}\left(L_{k}\right)\right)$ then: $\min \left(w_{j}, U_{j}^{-}\left(L_{k}^{*}\right)\right)=\min \left(w_{j}, U_{j}^{-}\left(L_{k}\right)\right)=w_{j}$

- Else if $\left(w_{j} \geq U_{j}^{-}\left(L_{k}\right)\right)$ then:

- If $\left(w_{j} \leq U_{j}^{-}\left(L_{k}^{*}\right)\right)$ then: $\min \left(w_{j}, U_{j}^{-}\left(L_{k}^{*}\right)\right)=w_{j} \leq \min \left(w_{j}, U_{j}^{-}\left(L_{k}\right)\right)=U_{j}^{-}\left(L_{k}\right)$

- If $\left(w_{j} \geq U_{j}^{-}\left(L_{k}^{*}\right)\right)$ then: $\min \left(w_{j}, U_{j}^{-}\left(L_{k}^{*}\right)\right)=U_{j}^{-}\left(L_{k}^{*}\right) \geq \min \left(w_{j}, U_{j}^{-}\left(L_{k}\right)\right)=U_{j}^{-}\left(L_{k}\right)$

Then, $\min \left(w_{j}, U_{j}^{-}\left(L_{k}^{*}\right)\right) \geq \min \left(w_{j}, U_{j}^{-}\left(L_{k}\right)\right)$

So, $\max _{j} \min \left(w_{j}, U_{j}^{-}\left(L_{k}^{*}\right)\right) \geq \max _{j} \min \left(w_{j}, U_{j}^{-}\left(L_{k}\right)\right)$

Proof (Proposition 7). We have defined $U_{\text {post }}^{+-}(L)=\min _{j=1, p} \max \left(\left(1-w_{j}\right), \max _{x_{i} \in X} \min \left(L\left[x_{i}\right], u_{j}\left(x_{i}\right)\right)\right)$ and $U_{j}^{+}(L)=\max _{x_{i} \in X} \min \left(L\left[x_{i}\right], u_{j}\left(x_{i}\right)\right)$ So, $U_{\text {post }}^{+-}(L)$ can be expressed as follows: $U_{\text {post }}^{+-}(L)=\min _{j=1, p} \max \left(\left(1-w_{j}\right), U_{j}^{+}(L)\right)$. 